\title{
Organic peroxides' gas-particle partitioning and rapid heterogeneous decomposition on secondary organic aerosol
}

\author{
Huan Li ${ }^{1}$, Zhongming Chen ${ }^{1}$, Liubin Huang ${ }^{1}$, and Dao Huang ${ }^{1, \mathrm{a}}$ \\ ${ }^{1}$ State Key Laboratory of Environmental Simulation and Pollution Control, College of Environmental Sciences and \\ Engineering, Peking University, Beijing 100871, China \\ ${ }^{a}$ now at: School of Earth Sciences, Zhejiang University, Hangzhou 310027, Zhejiang, China \\ Correspondence to: Zhongming Chen (zmchen@pku.edu.cn)
}

Received: 21 September 2015 - Published in Atmos. Chem. Phys. Discuss.: 20 October 2015

Revised: 18 January 2016 - Accepted: 2 February 2016 - Published: 17 February 2016

\begin{abstract}
Organic peroxides, important species in the atmosphere, promote secondary organic aerosol (SOA) aging, affect $\mathrm{HO}_{x}$ radicals cycling, and cause adverse health effects. However, the formation, gas-particle partitioning, and evolution of organic peroxides are complicated and still unclear. In this study, we investigated in the laboratory the production and gas-particle partitioning of peroxides from the ozonolysis of $\alpha$-pinene, which is one of the major biogenic volatile organic compounds in the atmosphere and an important precursor for SOA at a global scale. We have determined the molar yields of hydrogen peroxide $\left(\mathrm{H}_{2} \mathrm{O}_{2}\right)$, hydromethyl hydroperoxide (HMHP), peroxyformic acid (PFA), peroxyacetic acid (PAA), and total peroxides (TPOs, including unknown peroxides) and the fraction of peroxides in $\alpha$ pinene $/ \mathrm{O}_{3}$ SOA. Comparing the gas-phase peroxides with the particle-phase peroxides, we find that gas-particle partitioning coefficients of PFA and PAA are $10^{4}$ times higher than the values from the theoretical prediction, indicating that organic peroxides play a more important role in SOA formation than previously expected. Here, the partitioning coefficients of TPO were determined to be as high as (23) $\times 10^{-4} \mathrm{~m}^{3} \mu \mathrm{g}^{-1}$. Even so, more than $80 \%$ of the peroxides formed in the reaction remain in the gas phase. Water changes the distribution of gaseous peroxides, while it does not affect the total amount of peroxides in either the gas or the particle phase. Approx. $18 \%$ of gaseous peroxides undergo rapid heterogeneous decomposition on SOA particles in the presence of water vapor, resulting in the additional production of $\mathrm{H}_{2} \mathrm{O}_{2}$. This process can partially explain the unexpectedly high $\mathrm{H}_{2} \mathrm{O}_{2}$ yields under wet conditions. Transformation of organic peroxides to $\mathrm{H}_{2} \mathrm{O}_{2}$ also preserves $\mathrm{OH}$
\end{abstract}

in the atmosphere, helping to improve the understanding of $\mathrm{OH}$ cycling.

\section{Introduction}

Organic peroxides are important trace components in the atmosphere, serving as reservoirs of $\mathrm{HO}_{x}$ and $\mathrm{RO}_{x}$ radicals, participating in the formation of secondary organic aerosol (SOA), and causing adverse health effects as reactive oxygen species. Recently, peroxides were found to play a key role in the aging of SOA. The particle-bound organic peroxides undergo atmospheric photolysis with a lifetime of about 6 days (Epstein et al., 2014), and decline significantly within the mean SOA age of 4-7 days (Rudich et al., 2007). A laboratory experiment on the photolysis of SOA shows a high yield of hydroxyl radicals $(\mathrm{OH})$, which are considered to form from the decomposition of peroxides (Badali et al., 2015). This OH may cause the in-particle oxidation of SOA.

Model studies have tried to simulate the SOA formation in chamber experiments, but great discrepancies still exist between predicted and observed results (Camredon et al., 2010; Hoffmann et al., 1997; Griffin et al., 1999; Cocker III et al., 2001; Saathoff et al., 2009; Presto et al., 2005; Pye and Seinfeld, 2010; Farina et al., 2010). Jenkin (2004) added the formation of dimers and improved the simulation, especially at the beginning of SOA formation. Organic peroxides were found to be highly abundant in SOA (Ziemann, 2005; Docherty et al., 2005; Surratt et al., 2006; Nguyen et al., 2010; Bateman et al., 2011; Mertes et al., 2012; Epstein et al., 2014), possibly in the form of oligomers, which are even 
more important than carboxylic acids (Bonn et al., 2004). In order to improve the simulation of the production of SOA mass within the chamber, explicit parameters for gas-particle partitioning of organic peroxides are urgently needed.

The reactions and processes that generate or remove peroxides have been studied for many years. Cross-reactions of organic peroxy radicals $\left(\mathrm{RO}_{2}\right)$ and the hydroperoxy radical $\left(\mathrm{HO}_{2}\right)$ and self-reactions of $\mathrm{HO}_{2}$ are thought to be major sources of organic peroxides and hydrogen peroxide $\left(\mathrm{H}_{2} \mathrm{O}_{2}\right)$, respectively, in the atmosphere. Ozonolysis of biogenic volatile organic compounds (VOCs) also produces $\mathrm{H}_{2} \mathrm{O}_{2}$ in high yields although its mechanism is unknown (Zhang et al., 2009; Huang et al., 2013). Hydrolysis and reaction with $\mathrm{OH}$ are the main removal pathways for both organic peroxides and $\mathrm{H}_{2} \mathrm{O}_{2}$, and dry/wet deposition removes only a small portion of peroxides (Khan et al., 2015). However, existing theories about sources and removal of peroxides cannot account for the field observation results. Model simulations showed an overestimation on total peroxides (TPOs) and a underestimation on $\mathrm{H}_{2} \mathrm{O}_{2}$ as compared with field records in the airborne GABRIEL (Guyanas AtmosphereBiosphere exchange and Radicals Intensive Experiment with the Learjet) field campaign (Kubistin et al., 2010), indicating the existence of possible underestimated or new removal paths for organic peroxides and overestimated or new formation paths for $\mathrm{H}_{2} \mathrm{O}_{2}$. Field observations and laboratory experiments showed that particulate components, possibly particle-bound organic peroxides, could be transformed to $\mathrm{H}_{2} \mathrm{O}_{2}$. Arellanes et al. (2006) found that $\mathrm{H}_{2} \mathrm{O}_{2}$ in ambient SOA solution was 200-1000 times greater than expected levels based on the gas-liquid partitioning, implying that almost all $\mathrm{H}_{2} \mathrm{O}_{2}$ is generated from SOA solution. Wang et al. (2011) investigated several kinds of SOA derived from the oxidation of $\alpha$-pinene, $\beta$-pinene, and toluene, and came to the similar conclusion that more than $97.5 \% \mathrm{H}_{2} \mathrm{O}_{2}$ arose from SOA formation rather than from gas-liquid partitioning. However, this process happens in SOA solution and the amount of $\mathrm{H}_{2} \mathrm{O}_{2}$ produced by such a pathway is too small to account for the large discrepancy between observations and simulations for the gas-phase $\mathrm{H}_{2} \mathrm{O}_{2}$.

The effect of water on peroxides is complex. Laboratory experiments suggested that yields of particle-phase total peroxides in the ozonolysis of alkenes are not influenced by water vapor (Docherty et al., 2005). Unlike the total peroxides, yields of individual peroxides depend on relative humidity (RH). Yield of $\mathrm{H}_{2} \mathrm{O}_{2}$ increases under wet conditions (Becker et al., 1990; Hewitt and Kok, 1991; Simonaitis et al., 1991; Gäb et al., 1995; Huang et al., 2013), while the yields of bis-hydroxymethyl hydroperoxide and three unknown organic peroxides decrease under wet conditions (Huang et al., 2013). Theoretical studies suggest that water helps both the formation and decomposition of organic peroxides. Water can react with stabilized Criegee intermediates (SCIs) and generate hydroxyalkyl hydroperoxides (HAHPs). It has been proposed that not only isolated water molecules, but also wa- ter dimers react with SCIs, and the latter path could even be more important (Ryzhkov and Ariya, 2004). Numerous laboratory experiments support this proposal (Chao et al., 2015; Lewis et al., 2015; Berndt et al., 2014). As a result, the reaction with water dimers will be the largest sink for $\mathrm{CH}_{2} \mathrm{OO}$. However, the quantum chemical calculations predict that the larger SCIs react more slowly with water, both the water monomer and dimer (Vereecken et al., 2014). Water also helps gas-phase decomposition of HAHPs, although the decomposition rate constant is small according to the theoretical calculations (Crehuet et al., 2001; Aplincourt and Anglada, 2003).

This study investigates the ozonolysis of $\alpha$-pinene, which is considered as one of the largest contributors to SOA and a dominant source of organic peroxides on a global scale (Khan et al., 2015), focusing on the formation of peroxides in both the gas and the particle phase. Gas-particle partitioning and water effect are examined carefully.

\section{Material and methods}

\subsection{Chemicals}

$\alpha$-Pinene (Aldrich, 99\%), cyclohexane (Sigma-Aldrich, $\geq 99.7 \%$ ), potassium iodide (Alfa Aesar, 99.9\%), hydrogen peroxide (Alfa Aesar, $35 \mathrm{wt} \%$ ), orthophosphoric acid (Fluka, 85-90\%), hemin (Sigma, $\geq 98.0 \%$ ), 4hydroxyphenylacetic acid (Alfa Aesar, $99 \%$ ), ammonia solution $\left(\mathrm{NH}_{3} \cdot \mathrm{H}_{2} \mathrm{O}\right.$, Beijing Tongguang Fine Chemicals Company, 25.0-28.0\%), ammonium chloride $\left(\mathrm{NH}_{4} \mathrm{Cl}\right.$, Beijing Chemical Works, $\geq 99.5 \%)$, ultrapure water $(18 \mathrm{M} \Omega$, Millipore), $\mathrm{N}_{2}$ ( $\geq 99.999 \%$, Beijing Haikeyuanchang Practical Gas Company Limited, Beijing, China), $\mathrm{O}_{2}$ ( $\geq 99.999 \%$, Beijing Haikeyuanchang Practical Gas Company Limited, Beijing, China), and a polytetrafluoroethylene (PTFE) filter membrane (Whatman Inc., $47 \mathrm{~mm}$ in diameter) were used in this study.

\subsection{Apparatus and procedures}

A flow tube reactor $(2 \mathrm{~m}$ length, $70 \mathrm{~mm}$ inner diameter, quartz wall) equipped with a water jacket for controlling temperature was used to investigate the ozonolysis of $\alpha$-pinene. All the experiments were conducted at $298 \pm 0.5 \mathrm{~K}$ and in the dark. $\mathrm{O}_{3}$ was generated by the photolysis of $\mathrm{O}_{2}$ in a $2 \mathrm{~L}$ quartz tube with a low-pressure $\mathrm{Hg}$ lamp, and the detailed quantification method of $\mathrm{O}_{3}$ was described in our previous study (Chen et al., 2008). $\mathrm{O}_{3}(\sim 25 \mathrm{ppmv})$ was used in the experiments. $\alpha$-Pinene gas was generated by passing a flow of $\mathrm{N}_{2}$ over liquid $\alpha$-pinene in a diffusion tube at the selected controlled temperature. The initial concentration of $\alpha$-pinene, determined by a gas chromatography flame ionization detector (GC-FID, Agilent 7890A, USA), was $\sim 273 \mathrm{ppbv}$ in the experiments. Water vapor was generated by passing $\mathrm{N}_{2}$ through a water bubbler. The mixing gases, in- 
cluding $\alpha$-pinene, $\mathrm{O}_{3}$, and dry or wet synthetic air $\left(80 \% \mathrm{~N}_{2}\right.$ and $20 \% \mathrm{O}_{2}$ ), were continuously introduced into the reactor with a total flow rate of 4 standard $\mathrm{L} \mathrm{min}^{-1}$ (standard liters per minute) and a residence time of $120 \mathrm{~s}$. The relative humidity (RH) was controlled at two levels: $<0.5 \% \mathrm{RH}$ (dry conditions) and $60 \% \mathrm{RH}$ (wet conditions). Gas from the reactor ( 2 standard $\mathrm{L} \mathrm{min}^{-1}$ ) was directed into a coil collector and scrubbed by $\mathrm{H}_{3} \mathrm{PO}_{4}$ stripping solution $\left(5 \times 10^{-3} \mathrm{M}\right.$, $\mathrm{pH} 3.5$ ) for hydroperoxides analysis. SOA produced from the ozonolysis of $\alpha$-pinene was collected onto a PTFE filter for $4 \mathrm{~h}$ at a flow rate of 4 standard $\mathrm{L} \mathrm{min}^{-1}$, and the mass of SOA on the filter was immediately measured by a semi-micro balance (Sartorius, Germany). After that, each loaded filter was extracted with $20 \mathrm{~mL} \mathrm{H}_{3} \mathrm{PO}_{4}$ solution $\left(5 \times 10^{-3} \mathrm{M}, \mathrm{pH} 3.5\right)$ using a shaker (Shanghai Zhicheng ZWY 103D, China) at $180 \mathrm{rpm}$ and $4^{\circ} \mathrm{C}$ for $15 \mathrm{~min}$, and then the SOA solution was immediately analyzed to determine the particle-phase peroxides. Each SOA solution was analyzed seven times at different times to investigate the evolution of SOA solution.

To explore the effect of water vapor on the formation of peroxides in the ozonolysis, two-stage reaction experiments were designed and carried out. In the first stage, dry synthetic air $\left(2\right.$ standard $\left.\mathrm{L} \mathrm{min}^{-1}\right)$ with $\alpha$-pinene $(\sim 275 \mathrm{ppbv})$ and $\mathrm{O}_{3}(\sim 42$ ppmv) entered the first $2 \mathrm{~L}$ flow tube reactor; in the second stage, the gas passed through the second $2 \mathrm{~L}$ flow tube reactor but with the addition of dry or wet synthetic air ( 2 standard $\mathrm{L} \mathrm{min}^{-1}$ ). The residence time was $68 \mathrm{~s}$ in the first reactor and $34 \mathrm{~s}$ in the second reactor. The concentration of $\alpha$-pinene at the outlet of the first reactor was found to be below the GC-FID detection limit ( $<5 \mathrm{ppbv})$, meaning that $\alpha$-pinene was almost completely consumed before the gas entered the second reactor. Thus, water vapor appearing in the second reactor only affected the products from the first reactor. A filter was placed at the outlet of the first reactor or second reactor to collect SOA when necessary.

\subsection{Peroxides' analysis}

The low-weight molecular peroxides were measured using high-performance liquid chromatography (HPLC, Agilent 1100 , USA) coupled with a post-column derivatization module and fluorescence detection, and the concentration of total peroxides was determined by an iodometric spectrophotometer method. Details about the HPLC fluorescence method were reported in our previous study (Hua et al., 2008). Briefly, this method is based on the reaction of $p$ hydroxyphenylacetic acid (POPHA) with organic hydroperoxides or hydrogen peroxide in the catalysis of the hemin, forming POPHA dimer (2,2'-bisphenol-5, $5^{\prime}$-diacetic acid), which is a fluorescent substance, and then is quantified by a fluorescence detector. The separation of peroxides was implemented by column chromatography before the peroxides were reacted with POPHA. The synthetic method for organic peroxides standards is described in our previous study (Huang et al., 2013).
The iodometric spectrophotometric method is used to quantify all classes of peroxides (ROOR', ROOH, and $\mathrm{H}_{2} \mathrm{O}_{2}$ ), with the exception of tertiary dialkyl peroxides, in the aqueous phase without distinction (Banerjee and Budke, 1964). Peroxyhemiacetals formed in $\alpha$-pinene ozonolysis can be measured using this method. Excess potassium iodide reacts with peroxides, producing $\mathrm{I}_{3}^{-}$ions (Reaction $\mathrm{R} 1$ ), which can be quantified by UV/VIS spectrophotometry.

$3 \mathrm{I}^{-}+\mathrm{H}_{2} \mathrm{O}_{2}+2 \mathrm{H}^{+} \rightarrow \mathrm{I}_{3}^{-}+2 \mathrm{H}_{2} \mathrm{O}$

$\alpha$-Pinene SOA is freely soluble in polar solvents, e.g., water, acetonitrile, and methanol, but it is poorly soluble in nonpolar solvents, e.g., chloroform and toluene (Nguyen et al., 2010). Hence, a $\mathrm{H}_{3} \mathrm{PO}_{4}$ solution, as a kind of polar solvent, could entirely extract SOA from filters. The HPLC fluorescence method uses $\mathrm{H}_{3} \mathrm{PO}_{4}$ solution as a solvent for peroxides such as $\mathrm{H}_{2} \mathrm{O}_{2}$, hydromethyl hydroperoxide (HMHP), performic acid (PFA), and peracetic acid (PAA) which are more stable in acidic solution than in pure water (Zhou and Lee, 1992). In order to be comparable with the HPLC fluorescence method, SOA loaded filters were also extracted by $\mathrm{H}_{3} \mathrm{PO}_{4}$ solution. The influence of $\mathrm{pH}$ on extraction efficiency is discussed in the Supplement. In this study, SOA solution $(2.5 \mathrm{~mL})$ was added into a $10 \mathrm{~mL}$ airtight Micro-Reaction Vessel (Supelco, USA). Each solution was then purged of oxygen by bubbling with $\mathrm{N}_{2}$ for $5 \mathrm{~min}$. After purging, an aqueous solution of KI $(250 \mu \mathrm{L}, 0.75 \mathrm{M})$ was added into the vessel. The vessel was then capped tightly, covered with aluminium foil, and allowed to stand in the dark for $12-24 \mathrm{~h}$. The solution absorbance was then measured at $420 \mathrm{~nm}$ by an UV/VIS spectrophotometer (SHIMADZU UV-1800, Japan). The efficiency of peroxide measurements is discussed in the Supplement.

\section{Results and discussion}

\subsection{Gas-particle partitioning of peroxides}

\subsubsection{Particle-phase peroxides}

We measured the different mass values of SOA produced from the ozonolysis of $\alpha$-pinene at different RHs in the presence or absence of the $\mathrm{OH}$ scavenger cyclohexane, and found that the typical in-reactor SOA concentration was 450$650 \mu \mathrm{g} \mathrm{m}^{-3}$. A comparison of the aerosol mass yields $\left(Y_{\mathrm{SOA}}\right)$, defined as the ratio of the formed aerosol mass to the consumed $\alpha$-pinene mass, (Table 1) indicated that while the SOA yields were independent of the presence of water vapor, they decreased in the presence of $\mathrm{OH}$ scavenger.

Organic peroxides are considered to be one of the major constituents in SOA (Docherty et al., 2005; Ziemann, 2005; Surratt et al., 2006; Nguyen et al., 2010; Mertes et al., 2012; Kidd et al., 2014; Badali et al., 2015) (Table S1 in the Supplement). The sensitivity of the iodometric method to ROOR 
Table 1. Peroxide content in the gas phase and particle phase of $\alpha$-pinene ozonolysis as affected by the OH radical scavenger cyclohexane ${ }^{\mathrm{a}}$.

\begin{tabular}{|c|c|c|c|c|}
\hline \multirow{2}{*}{$\begin{array}{l}\text { OH scavenger } \\
\text { RH }\end{array}$} & \multicolumn{2}{|c|}{ None } & \multicolumn{2}{|c|}{ Cyclohexane } \\
\hline & $<0.5 \%$ & $60 \%$ & $<0.5 \%$ & $60 \%$ \\
\hline \multicolumn{5}{|l|}{ Gas phase } \\
\hline$Y_{\mathrm{H}_{2} \mathrm{O}_{2}}^{\mathrm{b}}$ & $0.048 \pm 0.012$ & $0.16 \pm 0.01$ & $0.048 \pm 0.010$ & $0.14 \pm 0.02$ \\
\hline$Y_{\mathrm{HMHP}}^{\mathrm{b}}$ & $0.0030 \pm 0.0003$ & $0.0062 \pm 0.0005$ & $0.0024 \pm 0.0005$ & $0.0037 \pm 0.0006$ \\
\hline$Y_{\mathrm{PFA}}^{\mathrm{b}}$ & $0.0057 \pm 0.0020$ & $0.012 \pm 0.002$ & $0.0020 \pm 0.0003$ & $0.005 \pm 0.001$ \\
\hline$Y_{\mathrm{PAA}}^{\mathrm{b}}$ & $0.0067 \pm 0.0006$ & $0.009 \pm 0.001$ & $0.0022 \pm 0.0002$ & $0.0024 \pm 0.0001$ \\
\hline$Y_{\mathrm{TPO}}^{\mathrm{b}}$ & $0.18 \pm 0.01$ & $0.20 \pm 0.01$ & $0.27 \pm 0.02$ & $0.25 \pm 0.02$ \\
\hline $\mathrm{H}_{2} \mathrm{O}_{2}(g) / \mathrm{TPO}(g)\left(\mathrm{ppbv}_{\mathrm{ppbv}}{ }^{-1}\right)$ & $0.26 \pm 0.02$ & $0.78 \pm 0.04$ & $0.18 \pm 0.02$ & $0.50 \pm 0.04$ \\
\hline \multicolumn{5}{|l|}{ Particle phase } \\
\hline$Y_{\mathrm{SOA}}^{\mathrm{c}}$ & $0.41 \pm 0.01$ & $0.39 \pm 0.02$ & $0.28 \pm 0.02$ & $0.27 \pm 0.01$ \\
\hline$F_{\mathrm{H}_{2} \mathrm{O}_{2}}^{\mathrm{d}}\left(\mathrm{ng} \mu \mathrm{g}^{-1}\right)$ & $5.09 \pm 0.99$ & $2.67 \pm 0.17$ & $1.61 \pm 0.11$ & $1.41 \pm 0.21$ \\
\hline$F_{\text {PFA }}^{\mathrm{d}^{2}}\left(n g \mu \mathrm{g}^{-1}\right)$ & $0.35 \pm 0.06$ & $0.27 \pm 0.02$ & $0.14 \pm 0.01$ & $0.16 \pm 0.04$ \\
\hline$F_{\mathrm{PAA}}^{\mathrm{d}^{\mathrm{A}}}\left(\mathrm{ng} \mu \mathrm{g}^{-1}\right)$ & $0.11 \pm 0.04$ & - & $0.09 \pm 0.01$ & - \\
\hline$F_{\mathrm{TPO}}^{\mathrm{d}}\left(\mu \mathrm{g} \mu \mathrm{g}^{-1}\right)$ & $0.23 \pm 0.01$ & $0.25 \pm 0.01$ & $0.16 \pm 0.01$ & $0.20 \pm 0.01$ \\
\hline $\mathrm{H}_{2} \mathrm{O}_{2}(p) / \mathrm{TPO}(p)\left(\mu \mathrm{M} \mu \mathrm{M}^{-1}\right)$ & $0.20 \pm 0.03$ & $0.10 \pm 0.01$ & $0.09 \pm 0.01$ & $0.06 \pm 0.01$ \\
\hline $\mathrm{TPO}(p) / \mathrm{TPO}(g+p)^{\mathrm{e}}$ & $0.19 \pm 0.02$ & $0.18 \pm 0.03$ & $0.07 \pm 0.01$ & $0.09 \pm 0.01$ \\
\hline
\end{tabular}

a $\sim 275$ ppbv $\alpha$-pinene, $\sim 1300$ ppmv cyclohexane, and $\sim 42$ ppmv $\mathrm{O}_{3}$ were used in these experiments; the data represent the mean \pm SD of three observations; ${ }^{b}$ molar yield of peroxides; ${ }^{c}$ mass yield of SOA; ${ }^{d}$ contribution of peroxides to SOA mass; ${ }^{\mathrm{e}}$ fraction of particulate TPO in gaseous and

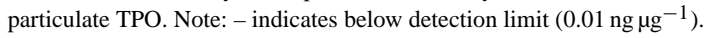

is critical to obtain an accurate concentration of total peroxides since peroxyhemiacetals are a significant component (Docherty et al., 2005). In the present study, we determined the total molar concentration of peroxides in SOA using the iodometric method. Stability of peroxides in SOA stored onfilter was also tested, and the results show that peroxides' concentration decrease with increasing sitting time (Fig. S4 in the Supplement). Hence, the peroxides in SOA were determined immediately after collection. Here, the mass fraction of peroxides in SOA ( $\left.F_{\text {peroxides }}\right)$ is defined as the ratio of mass of particle-bound peroxides to SOA mass, which is defined as follows:

$F_{\text {peroxides }}=\frac{m_{\text {peroxides }}}{m_{\mathrm{SOA}}}$,

where $m_{\text {peroxides }}$ is the mass of particle-bound peroxides, such as PFA, PAA, and TPO, and $m_{\mathrm{SOA}}$ is the mass of SOA. Assuming that the average molecular weight of peroxides is 300 , we obtained the mass fraction of total peroxides in SOA $\left(F_{\mathrm{TPO}}\right)$ as $\sim 0.21$ (Table 1$)$, which is consistent with 0.22 reported by Epstein et al. (2014), but less than 0.47 reported by Docherty et al. (2005) and 0.34 reported by Mertes et al. (2012). Several factors, such as the presence of $\mathrm{OH}$ scavengers, reactor type, extraction method, SOA mass measurements, and SOA density assumptions, may cause these discrepancies. In addition to the concentration of total peroxides, we measured the concentration of two small organic peroxides peroxyformic acid (PFA) and peroxyacetic acid (PAA) in SOA and calculated the con- tribution of PFA $\left(F_{\mathrm{PFA}}\right)$ and PAA $\left(F_{\mathrm{PAA}}\right)$ to SOA mass (Table 1$)$. Under dry conditions, the $F_{\mathrm{PFA}}$ and $F_{\mathrm{PAA}}$ were $0.35 \pm 0.06$ and $0.11 \pm 0.04 \mathrm{ng}_{\mu \mathrm{g}}{ }^{-1}$, respectively, without

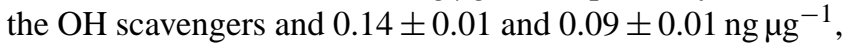
respectively, with cyclohexane. After adding water vapor, $F_{\text {PFA }}$ did not significantly change, but $F_{\text {PAA }}$ approached 0 .

\subsubsection{Gas-phase peroxides}

In addition to the particle-phase peroxides, we measured the gas-phase peroxides generated in the ozonolysis of $\alpha$-pinene. Here, the molar yield of gaseous peroxides ( $\left.Y_{\text {peroxides }}\right)$ is defined in Eq. (2):

$Y_{\text {peroxides }}=\frac{\Delta \text { peroxides }}{\Delta \alpha \text {-pinene }}$,

where $\Delta$ peroxides are moles of gaseous peroxides formed, such as HMHP, PFA, PAA, and TPO, and $\Delta \alpha$-pinene are moles of consumed $\alpha$-pinene. The molar yield of total peroxides $\left(Y_{\mathrm{TPO}}\right)$ was estimated to be nearly the same under both dry conditions and wet conditions in the absence of $\mathrm{OH}$ scavengers (Table 1), indicating that total yield of peroxides was unaffected by water vapor. Moreover, when we employed the Master Chemical Mechanism (MCM) v3.1 mechanism to simulate the present reaction system, the modeled yield of total peroxides was about 0.25 , consistent with our experimental result. The model results also suggested that hydroperoxides account for more than $99 \%$ of total peroxides. The yields of HMHP $\left(Y_{\mathrm{HMHP}}\right)$, PFA $\left(Y_{\mathrm{PFA}}\right)$, and PAA 
$\left(Y_{\mathrm{PAA}}\right)$ are shown in Table 1. Compared with dry conditions, $Y_{\mathrm{HMHP}}$ and $Y_{\mathrm{PFA}}$ doubled under wet conditions, while $Y_{\mathrm{PAA}}$ increased only slightly. However, yields of these three organic peroxides were all lower in the presence of $\mathrm{OH}$ scavengers, indicating the importance of $\mathrm{OH}$ in the formation of small organic peroxides.

Considering that all the peroxides originally existed in the gas phase at the beginning of the ozonolysis of $\alpha$-pinene, we estimated the fraction of peroxides that entered the particulate phase from the gas phase through gas-particle partition based on measured peroxides in the particle and gas phases. The fraction of particulate TPO in gaseous and particulate TPOs (TPO $(p) / \operatorname{TPO}(g+p))$ was essentially the same (Table 1) under both wet and dry conditions. To the best of our knowledge, for the ozonolysis of $\alpha$-pinene, this is the first report of the yield of gas-phase total peroxides (including hydrogen peroxide and organic peroxides) and the gas-particle partitioning fraction.

The gas-particle partitioning coefficient $\left(K_{\mathrm{p}}\right)$ describes the partitioning ability of a given species, calculated as follows (Odum et al., 1996):

$K_{\mathrm{p}}=\frac{C_{\mathrm{a}}}{C_{\mathrm{g}} C_{\mathrm{om}}}$,

where $C_{\mathrm{a}}$ is the concentration of this species in the aerosol phase, $\mu \mathrm{g} \mathrm{m}^{-3} ; C_{\mathrm{g}}$ is the concentration of this species in the gas phase, $\mu \mathrm{g} \mathrm{m}^{-3}$; and $C_{\mathrm{om}}$ is the total concentration of condensed organic matter, $\mu \mathrm{g} \mathrm{m}^{-3}$. Based on the gas-phase peroxides' concentration, particle-phase peroxides' concentration, and the aerosol yields summarized in Table 1, we can obtain the observed $K_{\mathrm{p}}$ (Table 2).

The Pankow absorption model (Pankow, 1994) is the most widely accepted mechanism to explain the gas-particle partitioning, and has been used to predict aerosol yields in chamber experiments (Cocker III et al., 2001; Jenkin, 2004; Yu et al., 1999). Theoretical $K_{\mathrm{p}}$ can be calculated by the following equation:

$K_{\mathrm{p}}=\frac{7.501 \times 10^{-9} R T}{\mathrm{MW}_{\mathrm{om}} \varsigma p_{\mathrm{L}}^{\circ}}$,

where $R$ is the ideal gas constant, $\mathrm{JK}^{-1} \mathrm{~mol}^{-1} ; T$ is the temperature, $\mathrm{K} ; \mathrm{MW}_{\mathrm{om}}$ is the mean molecular weight of the condensed organic material, $\mathrm{g} \mathrm{mol}^{-1}$. In the present study, $\mathrm{MW}_{\mathrm{om}}$ is estimated to be $130 \mathrm{~g} \mathrm{~mol}^{-1}$; $\varsigma$ is the activity coefficient of the given species in the condensed organic phase, and here, is assumed to be unity; $p_{\mathrm{L}}^{\circ}$ is the liquid vapor pressure of this species, Torr. The theoretical $p_{\mathrm{L}}^{\circ}$ can be calculated by an expended, semiempirical form of the ClausiusClapeyron equation (Baum, 1997). Theoretical gas-particle partitioning coefficients of PFA and PAA are shown in Table 2 .

The observed gas-particle partitioning coefficients of PFA, PAA, and TPO were (3-9) $\times 10^{-5},(2-4) \times 10^{-5}$, and $(2-$ 3) $\times 10^{-4} \mathrm{~m}^{3} \mu \mathrm{g}^{-1}$, respectively (Table 2 ), which, to the best of our knowledge, are reported here for the first time. However, the long time collection for SOA does have effects on gas- and particle-phase constituents, possibly due to repartitioning of species between the two phases. Collected SOA mass and peroxide amount per unit time decreases slightly with increasing collection time, and peroxide amount decreases faster than SOA mass (Supplement). Hence, the gasparticle partitioning coefficients of peroxides given here are underestimated by about $21 \%$. Compared with the observed $K_{\mathrm{p}}$ values, theoretical $K_{\mathrm{p}}$ values of PFA and PAA, $2 \times 10^{-9}$ and $4 \times 10^{-9} \mathrm{~m}^{3} \mathrm{\mu g}^{-1}$, respectively, were lower by a factor of $10^{4}$. This large difference between observed and theoretical $K_{\mathrm{p}}$ values has also been reported previously (Cocker III et al., 2001; Jenkin, 2004; Kamens and Jaoui, 2001). Jenkin (2004) considered the existence of a significant systematic error, which is independent of key parameters involved in prediction of $K_{\mathrm{p}}$ values, or the inability to interpret the Pankow absorption model. After inducing a speciesindependent scaling factor of ca. 120 for all partitioning species, Jenkin obtained a reasonable simulation of the final experimental aerosol concentration, but was still unable to interpret the early stages of aerosol accumulation. In addition to the absorptive partitioning mechanism, the participation of bi- and multifunctional acid dimers in the aerosol formation process was also considered, resulting in the presentation of simulated results. Organic peroxides are also important compounds in dimer formation; for instance, hydroperoxides can react with aldehydes, subsequently producing peroxyhemiacetals (Tobias and Ziemann, 2000, 2001; Ziemann, 2005). The vapor pressures of hydroperoxides decreased in the formation of peroxyhemiacetals by an additional factor of $\sim 10^{2}-10^{5}$ (Tobias and Ziemann, 2000), which could partially explain the large discrepancy between the observed and theoretical gas-particle partitioning coefficient. However, related thermodynamic and kinetic parameters need further study to resolve the problem.

\subsection{Evolution of SOA in the aqueous phase}

We investigated the evolution of SOA in the aqueous phase, focusing on the change of $\mathrm{H}_{2} \mathrm{O}_{2}$ in SOA. The initial concentration of $\mathrm{H}_{2} \mathrm{O}_{2}$ was low, but it increased rapidly in the first $3.5 \mathrm{~h}$, approaching the peak at $\sim 7.5 \mathrm{~h}$, and then decreased slowly, meaning the existence of a sustained release of $\mathrm{H}_{2} \mathrm{O}_{2}$ in the SOA solution at room temperature $(298 \mathrm{~K})$ (Fig. 1). The molar fraction of peak $\mathrm{H}_{2} \mathrm{O}_{2}$ to total peroxides in SOA $\left(\mathrm{H}_{2} \mathrm{O}_{2}(p) / \mathrm{TPO}(p)\right)$ under dry conditions was twice as high as that observed under wet conditions in the absence of $\mathrm{OH}$ scavengers (Table 1). The contribution of $\mathrm{H}_{2} \mathrm{O}_{2}$ to the SOA mass $\left(F_{\mathrm{H}_{2} \mathrm{O}_{2}}\right)$ was 1.9 times higher under dry conditions $\left(5.09 \pm 0.99 \mathrm{ng} \mathrm{\mu g}^{-1}\right)$ than under wet conditions $\left(2.67 \pm 0.17 \mathrm{ng} \mathrm{\mu g}^{-1}\right)$ (Table 1$)$. In the presence of cyclohexane, $\mathrm{H}_{2} \mathrm{O}_{2}(p) / \mathrm{TPO}(p)$ was slightly higher under dry conditions than wet conditions $(0.09 \pm 0.01$ and $0.06 \pm 0.01$, respectively), while $F_{\mathrm{H}_{2} \mathrm{O}_{2}}$ values were not significantly af- 
Table 2. Comparison of observed and theoretical gas-particle partitioning coefficients $\left(K_{\mathrm{p}}\right)$ of PFA, PAA, and TPO at different scenarios $(298 \mathrm{~K})$.

\begin{tabular}{|c|c|c|c|c|c|}
\hline & \multicolumn{4}{|c|}{$\begin{array}{c}K_{\mathrm{p}}(\text { observed }) \\
\left(\mathrm{m}^{3} \mu \mathrm{g}^{-1}\right)^{\mathrm{a}}\end{array}$} & \multirow[t]{2}{*}{$\begin{array}{r}K_{\mathrm{p}}(\text { theoretical }) \\
\left(\mathrm{m}^{3} \mu \mathrm{g}^{-1}\right)\end{array}$} \\
\hline & Sc1 & $\mathrm{Sc} 2$ & $\mathrm{Sc} 3$ & Sc4 & \\
\hline PFA & $8.06 \times 10^{-5}$ & $2.95 \times 10^{-5}$ & $9.19 \times 10^{-5}$ & $4.20 \times 10^{-5}$ & $2 \times 10^{-9}$ \\
\hline PAA & $1.76 \times 10^{-5}$ & - & $4.38 \times 10^{-5}$ & - & $4 \times 10^{-9}$ \\
\hline TPO & $3.47 \times 10^{-4}$ & $3.39 \times 10^{-4}$ & $1.61 \times 10^{-4}$ & $2.17 \times 10^{-4}$ & - \\
\hline
\end{tabular}

a The four scenarios represent four reaction conditions: $\mathrm{Sc} 1(<0.5 \% \mathrm{RH}$, no OH scavenger), Sc2 (60\% RH, no OH scavenger), Sc3 ( $<0.5 \% \mathrm{RH}$, with cyclohexane), and Sc4 (60\% RH, with cyclohexane). Cyclohexane used here was $\sim 1300$ ppmv.

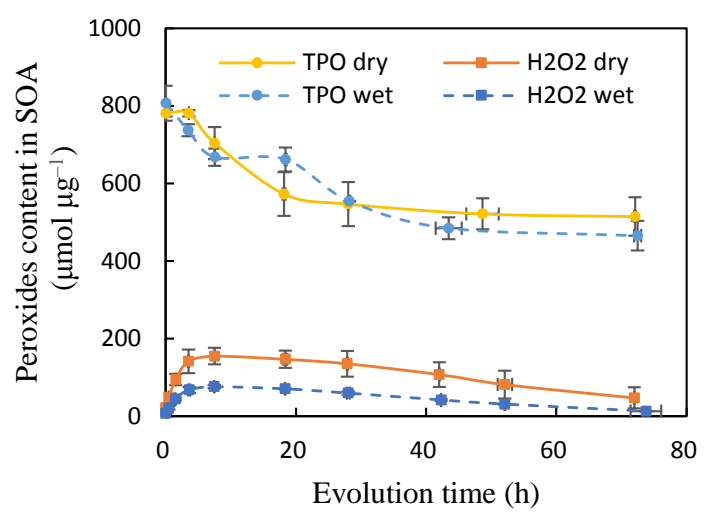

Figure 1. Evolution of total peroxides and $\mathrm{H}_{2} \mathrm{O}_{2}$ contents in SOA produced under dry $(<0.5 \% \mathrm{RH})$ and wet $(60 \% \mathrm{RH})$ conditions at $298 \mathrm{~K}$. Circles and squares represent total peroxides and $\mathrm{H}_{2} \mathrm{O}_{2}$ contents in SOA, respectively; and solid lines and dashed lines represent that obtained under dry and wet conditions, respectively. The data represent the mean $\pm \mathrm{SD}$ of three observations.

fected by RH (Table 1). Our observations are consistent with those of Wang et al. (2011) who studied $\alpha$-pinene-derived SOA, and measured the $F_{\mathrm{H}_{2} \mathrm{O}_{2}}$ as $2.01 \pm 0.76 \mathrm{ng} \mathrm{\mu g}^{-1}$, which was unchanged by a variety of oxidants (NO/light, $\mathrm{O}_{3}$, and $\mathrm{O}_{3} /$ cyclohexane) over the range of $14-43 \% \mathrm{RH}$.

The sustained release of $\mathrm{H}_{2} \mathrm{O}_{2}$ coupled with the attenuation of total peroxides provided experimental evidence for the hypothesis that the decomposition/hydrolysis of organic peroxides generates $\mathrm{H}_{2} \mathrm{O}_{2}$. The decay of $\mathrm{H}_{2} \mathrm{O}_{2}$ in SOA solution after $18 \mathrm{~h}$ is a comprehensive phenomenon including formation and decomposition, and the rate was estimated to be 0.06 and $0.03 \mu \mathrm{Mh}^{-1}$ for SOA produced under dry and wet conditions, respectively. To assess the formation, we determined the decomposition rates of pure $\mathrm{H}_{2} \mathrm{O}_{2}$ at different concentrations. When the $\mathrm{H}_{2} \mathrm{O}_{2}$ concentration was $\sim 5 \mu \mathrm{M}(\sim 2.5 \mu \mathrm{M})$, the rate of decomposition was $0.11 \mu \mathrm{Mh}^{-1}\left(0.05 \mu \mathrm{Mh}^{-1}\right)$. The $\mathrm{H}_{2} \mathrm{O}_{2}$ concentrations were equivalent with those of $\mathrm{H}_{2} \mathrm{O}_{2}$ in SOA solution. Thus, we can estimate $\mathrm{H}_{2} \mathrm{O}_{2}$ formation in the SOA solution after $18 \mathrm{~h}$ to have a rate of $0.05 \mu \mathrm{M} \mathrm{h}^{-1}$ under dry conditions

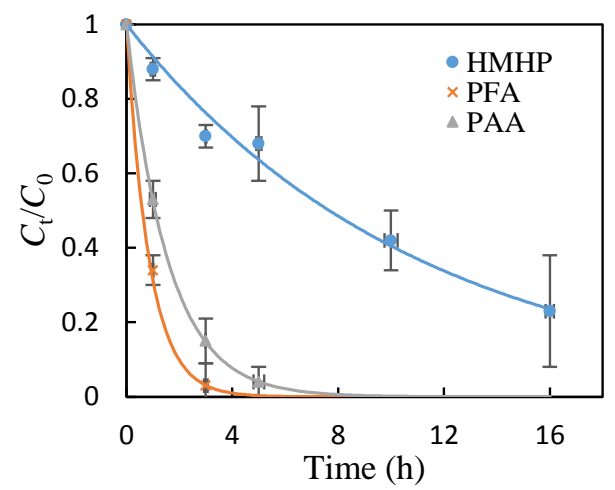

Figure 2. Decomposition/hydrolysis of organic peroxides in the aqueous phase. $C_{t} / C_{0}$ is the ratio of peroxides' concentration at time $=t \mathrm{~h}$ to peroxides concentration at time $=0 \mathrm{~h}$. Lines are exponential fits for HMHP, PFA, and PAA. The decay rate constants of HMHP, PFA, and PAA are $0.09,1.06$, and $0.64 \mathrm{~h}^{-1}$, respectively. The data represent the mean $\pm \mathrm{SD}$ of three observations.

and $0.02 \mu \mathrm{Mh}^{-1}$ under wet conditions. As shown in Fig. 2, the peroxycarboxylic acids (PCAs) (PFA and PAA), decayed quickly while the HAHP (HMHP) decayed slowly. Hence, the formation of $\mathrm{H}_{2} \mathrm{O}_{2}$ after $18 \mathrm{~h}$ could be attributed to the decomposition of HAHPs. However, in the first $7.5 \mathrm{~h}$ period, $\mathrm{H}_{2} \mathrm{O}_{2}$ increased rapidly which is more consistent with the decay of PCAs rather than HAHPs. Not all the organic peroxides decayed during the observation time, since the attenuation of TPO almost stopped after $40 \mathrm{~h}$. The residual peroxides were more stable, possibly due to the formation of ROOR by oligomerization.

\subsection{Unexpectedly high levels of $\mathrm{H}_{2} \mathrm{O}_{2}$ in the gas phase}

Table 1 shows the molar yields of gas-phase $\mathrm{H}_{2} \mathrm{O}_{2}$. The $\mathrm{H}_{2} \mathrm{O}_{2}$ yield in the absence and presence of cyclohexane was essentially the same in dry conditions, but under conditions of high RH increased to $0.16 \pm 0.01$ in control studies and to $0.14 \pm 0.02$ in the presence of cyclohexane. Thus, the presence of water vapor elevated the $\mathrm{H}_{2} \mathrm{O}_{2}$ yield, while the presence of a radical scavenger had no effect. Previous studies on 
gas-phase $\mathrm{H}_{2} \mathrm{O}_{2}$ yields of the ozonolysis of $\alpha$-pinene are reviewed (Table S2). Becker et al. (1990) first reported that the presence of water vapor will significantly promote the $\mathrm{H}_{2} \mathrm{O}_{2}$ yield, and our work confirmed this observation. However, our measured values of $\mathrm{H}_{2} \mathrm{O}_{2}$ were 10 times higher than those reported by others under both dry and wet conditions, except that by Simonaitis et al. (1991). Differences in reactant concentration, reactor type, and measuring methods account for these discrepancies. Worth noting is that the reactants' concentrations used in these previous and our experiments are very high, therefore, yields of peroxides may not represent actual yields of peroxides in oxidation of $\alpha$-pinene in nature (Supplement).

The source of gas-phase $\mathrm{H}_{2} \mathrm{O}_{2}$ remains unclear. We suggest that further ozonolysis and $\mathrm{OH}$ oxidation of gaseous products and reactants in the aqueous phase during and after gas collection are not likely to be the main sources of $\mathrm{H}_{2} \mathrm{O}_{2}$. In this study, the online GC-FID test showed that $\alpha$ pinene was completely consumed in the gas phase. Hence, the contribution of aqueous-phase $\alpha$-pinene ozonolysis to the measured $\mathrm{H}_{2} \mathrm{O}_{2}$ in the coil collector should be negligible. The main gas-phase non-peroxy organic products of $\alpha$-pinene ozonolysis are carbonyls and organic acids, e.g., pinonaldehyde, formaldehyde, acetone, and pinic acid; these compounds without carbon-carbon double bonds cannot be oxidized by $\mathrm{O}_{3}$. The ozonolysis of $\alpha$-pinene produces the $\mathrm{OH}$ radical in high yield (0.68-0.91) (Berndt et al., 2003), which potentially oxidizes carbonyls and organics. However, we observed no difference of $Y_{\mathrm{H}_{2} \mathrm{O}_{2}}$ in the absence and presence of $\mathrm{OH}$ scavengers, indicating that $\mathrm{OH}$ oxidation in the aqueous phase may not be a source of $\mathrm{H}_{2} \mathrm{O}_{2}$.

Decomposition/hydrolysis of organic peroxides in the aqueous phase during and after gas collection is also found to be a minor source of gas-phase $\mathrm{H}_{2} \mathrm{O}_{2}$. HAHPs and PCAs, two kinds of organic peroxides, are the probable candidates for generating $\mathrm{H}_{2} \mathrm{O}_{2}$. HAHPs are the main products of the reaction of SCI with water molecules and dimers (Ryzhkov and Ariya, 2004), and they can decompose to $\mathrm{H}_{2} \mathrm{O}_{2}$ plus the corresponding aldehyde, or $\mathrm{H}_{2} \mathrm{O}$ plus the corresponding organic acid (Hellpointner and Gäb, 1989). The hydrolysis of PCAs, which are generated from the reaction of $\mathrm{RC}(\mathrm{O}) \mathrm{OO}$ with $\mathrm{HO}_{2}$, is another possible source of $\mathrm{H}_{2} \mathrm{O}_{2}$. Several kinds of PCAs have been qualitatively observed in the ozonolysis of $\alpha$-pinene (Venkatachari and Hopke, 2008). In this study, we quantitatively observed PFA and PAA in the gas phase (Table 1), and simulated the formation of PCAs using the MCM v3.1 mechanism. Model results showed that the yield of total PCAs was extremely low, 0.0005 , and PAA contributed more than half of the yield, while the formation pathway of PFA was not included. The large discrepancy between modeled and experimental results indicates that PCAs play a more important role than was expected previously. We estimate the $\mathrm{H}_{2} \mathrm{O}_{2}$ generated from organic peroxides in the aqueous phase by measuring the decomposition/hydrolysis rate of organic peroxides. Considering the effects of concentration, coexist- ing components, and ionic strength, we conducted the measurements with coil collection solutions rather than with synthesized samples. The decomposition/hydrolysis of organic peroxides is a pseudo-first-order reaction due to the excess of the other reactant, i.e., water. The decay rate constants of HMHP, PFA, and PAA were determined to be $0.09,1.06$, and $0.64 \mathrm{~h}^{-1}$, respectively (Fig. 2). Larger HAHPs were less active compared with HMHP and should have lower decay rate constants. If all the TPOs are composed of HAHPs and the production of $\mathrm{H}_{2} \mathrm{O}_{2}$ plus aldehydes is the only decomposition pathway of HAHPs, the upper bound of $\mathrm{H}_{2} \mathrm{O}_{2}$ formed in the aqueous phase within 8 min may be estimated to be $1.2 \%$ of TPO. However, the observed ratio of gas-phase $\mathrm{H}_{2} \mathrm{O}_{2}$ to TPO was 28-78\%, indicating that the aqueous-phase decomposition of HAHPs is insignificant. Compared with HMHP, the decay rates of PFA and PAA were quite high. Assuming that all the TPOs, except for PFA, are PCAs and their decay rates were the same as that of PAA, $\mathrm{H}_{2} \mathrm{O}_{2}$ formed in the aqueous phase within $8 \mathrm{~min}$ is estimated to be $13.2 \%$ of TPO, which can partially explain the observed $\mathrm{H}_{2} \mathrm{O}_{2}$ level. However, the yield of PCAs in the ozonolysis of $\alpha$-pinene is predicted to be low in the MCM v3.1 model. The experimental results mentioned above concluded that the aqueousphase formation of $\mathrm{H}_{2} \mathrm{O}_{2}$ is not important, for the decay rate of HAHPs was too slow, and the amount of PCAs was too low, although their decay rate was higher.

Whether the self-reaction of $\mathrm{HO}_{2}$ and decomposition of HAHP in the gas phase are the main sources of $\mathrm{H}_{2} \mathrm{O}_{2}$ is discussed here. The self-reaction of $\mathrm{HO}_{2}$ is considered to be the main source of ambient $\mathrm{H}_{2} \mathrm{O}_{2}$ (Lee et al., 2000; Reeves and Penkett, 2003) and occurs in the ozonolysis of $\alpha$-pinene. When we estimated the contribution of this pathway to the observed $\mathrm{H}_{2} \mathrm{O}_{2}$ from $\alpha$-pinene ozonolysis using MCM v3.1 mechanisms, the yield was less than 0.001 under both dry and wet conditions, meaning that this pathway is negligible. Chamber experiments showed that SCI mainly reacts with water molecules even under dry conditions (Jenkin, 2004), and the major product is HAHP. Aplincourt and Anglada (2003) considered that the unimolecular decomposition of gaseous HAHPs was unlikely to occur, and only the water-assisted decomposition was efficient in the gas phase. They estimated the water-assisted decomposition rate constant of 2-propenyl $\alpha$-hydroxy hydroperoxide to be $1.5 \times 10^{-30} \mathrm{~cm}^{3}$ molecule $\mathrm{s}^{-1} \mathrm{~s}^{-1}$ by quantum chemical calculation. Based on their work, the gas-phase decomposition fraction of HAHP in 2 min can be calculated to be less than $0.01 \%$, which is too small to account for the $\mathrm{H}_{2} \mathrm{O}_{2}$ observed in our experiments.

In summary, the high $\mathrm{H}_{2} \mathrm{O}_{2}$ yields in the gas phase cannot be explained by the bias caused by measuring method and the current formation mechanism of $\mathrm{H}_{2} \mathrm{O}_{2}$. An unknown or underestimated pathway producing $\mathrm{H}_{2} \mathrm{O}_{2}$ may exist. In Sect. 3.4, we propose that gaseous organic peroxides can undergo rapid heterogeneous decomposition in the presence of water and produce $\mathrm{H}_{2} \mathrm{O}_{2}$. 
Table 3. Hydrogen peroxide in the coil collector at different scenarios in the two-stage experiments.

\begin{tabular}{lllrl}
\hline Scenarios & Filter position $^{\mathrm{a}}$ & Water vapor $^{\mathrm{b}}$ & $\mathrm{H}_{2} \mathrm{O}_{2}$ & Species in second reactor \\
\hline $1 \mathrm{~d}$ & Second reactor & No & $100 \pm 1 \%$ & Gaseous products, SOA \\
$1 \mathrm{w}$ & Second reactor & Yes & $165 \pm 6 \%$ & Gaseous products, SOA, water vapor \\
$2 \mathrm{~d}$ & First reactor & No & $103 \pm 6 \%$ & Gaseous products \\
$2 \mathrm{w}$ & First reactor & Yes & $87 \pm 7 \%$ & Gaseous products, water vapor \\
$3 \mathrm{~d}$ & No filter & No & $164 \pm 9 \%$ & Gaseous products, SOA \\
$3 \mathrm{w}$ & No filter & Yes & $172 \pm 5 \%$ & Gaseous products, SOA, water vapor \\
\hline
\end{tabular}

\subsection{Rapid heterogeneous decomposition of gaseous organic peroxides}

Our results demonstrate that water vapor has no significant effect on either the yield of total peroxides (combining gaseous and particulate peroxides) or the contribution of peroxides to SOA mass. However, water vapor does change the concentrations of $\mathrm{H}_{2} \mathrm{O}_{2}, \mathrm{PFA}$, and PAA in the gas phase and particle phase in an opposite manner (Table 1 ). In the presence of water vapor, $\mathrm{H}_{2} \mathrm{O}_{2}$ yield increased dramatically by $\sim 300 \%$, and gas-phase $\mathrm{H}_{2} \mathrm{O}_{2} /$ TPO increased from 0.26 to 0.78. Yields of HMHP, PFA, and PAA also increased with the presence of water vapor. These results clearly indicate that water vapor can change the formation and distribution of peroxides.

We carried out a series of two-stage experiments using two reactors under various scenarios to further study the effect of water vapor on peroxides (Table 3). In scenario 1d, no water vapor was added and a filter was used to intercept SOA entering the coil collector, which is similar to measuring $\mathrm{H}_{2} \mathrm{O}_{2}$ under dry conditions with one reactor. The concentration of $\mathrm{H}_{2} \mathrm{O}_{2}$ observed in the coil collection solution under this condition was considered to be the baseline value, $100 \%$. When the filter was placed at the outlet of the first reactor (scenario $2 \mathrm{~d}$ ) instead of at the second reactor, the concentration of $\mathrm{H}_{2} \mathrm{O}_{2}$ was $103 \pm 6 \%$, almost the same as the baseline, indicating that the coexistence of gaseous products and SOA will not lead to the formation of $\mathrm{H}_{2} \mathrm{O}_{2}$. In scenario $2 \mathrm{w}$, a filter was placed at the outlet of the first reactor and water vapor was added to the second reactor, resulting in the coexistence of gaseous products and water vapor $(50 \% \mathrm{RH})$ in the second reactor. The concentration of $\mathrm{H}_{2} \mathrm{O}_{2}$ observed in this scenario was $87 \%$, slightly lower than the baseline, possibly due to loss on the wall of the reactor under wet conditions, which has been reported to be $5 \%$ for $\mathrm{H}_{2} \mathrm{O}_{2}$ at $50 \%$ RH (Huang et al., 2013). When we maintained the water vapor and moved the filter to the outlet of the second reactor (scenario $1 \mathrm{w}$ ), the $\mathrm{H}_{2} \mathrm{O}_{2}$ concentration increased to $165 \pm 6 \%$ of baseline. In scenario $3 \mathrm{w}$, with water vapor added to the second reactor and without a filter in the gas flow, the $\mathrm{H}_{2} \mathrm{O}_{2}$ concentration was $172 \pm 5 \%$, almost the same as that in scenario $1 \mathrm{w}$. In scenario $3 \mathrm{~d}$, no water vapor and no filter were used, but a high $\mathrm{H}_{2} \mathrm{O}_{2}$ concentration, $164 \pm 9 \%$, was also observed. For scenarios $1 \mathrm{w}, 3 \mathrm{w}$, and $3 \mathrm{~d}$, where $\mathrm{H}_{2} \mathrm{O}_{2}$ increased by $\sim 67 \%$, gaseous products, SOA, and water were all present in the second reactor or coil collector. The coexistence of gaseous products and water vapor (see scenario $2 \mathrm{~d}$ and $2 \mathrm{w}$ ), the coexistence of gaseous products and SOA (see scenario $1 \mathrm{~d}$ and $2 \mathrm{~d}$ ), and the coexistence of SOA and water (see Sect. 3.3) did not result in a high yield of $\mathrm{H}_{2} \mathrm{O}_{2}$. We therefore concluded that the presence of three components together, the gaseous products, SOA, and water, was necessary for a high yield of $\mathrm{H}_{2} \mathrm{O}_{2}$. Once the gaseous products and SOA had been in contact with water vapor in the second reactor, the levels of $\mathrm{H}_{2} \mathrm{O}_{2}$ were increased to the same extent, whether or not these compounds were mixed with condensed water (see scenario $1 \mathrm{w}$ and $3 \mathrm{w}$ ), indicating that the process producing $\mathrm{H}_{2} \mathrm{O}_{2}$ in the gas phase is quite rapid.

When we measured the total peroxides formed from gaseous products and SOA in scenarios $1 \mathrm{~d}$ and $1 \mathrm{w}$, the results showed that for these two scenarios, the levels of the total peroxides in both gaseous products and SOA were not significantly different, indicating that SOA does not change in the presence of water vapor and no new peroxides are formed in the gas phase. This outcome supports the idea that the increment of $\mathrm{H}_{2} \mathrm{O}_{2}$ comes from the redistribution of gaseous peroxides, which is induced by the heterogeneous decomposition of gaseous products in the presence of both SOA and water. Based on the measured increment of $\mathrm{H}_{2} \mathrm{O}_{2}$ and concentration of gaseous total peroxides, we concluded that $18 \%$ of the gaseous total peroxides undergo rapid heterogeneous decomposition.

Heterogeneous reactions of trace gases on the surface of particles relevant to the atmosphere have been studied for many years. The investigated trace gases, including nitrogen oxides (e.g., $\mathrm{HNO}_{3}, \mathrm{NO}_{2}$, and $\mathrm{N}_{2} \mathrm{O}_{5}$ ), $\mathrm{SO}_{2}, \mathrm{O}_{3}, \mathrm{H}_{2} \mathrm{O}_{2}$, and oxygenated VOCs (Liggio et al., 2005; Kroll et al., 2005; Prince et al., 2007; Zhao et al., 2010, 2011, 2014; Huang et al., 2015), could react with the active sites on the surfaces of mineral dust (Goodman et al., 2001; Fu et al., 2007). Unlike mineral dust, however, SOA has no such active sites. The elucidation of the mechanism of the rapid heterogeneous de- 
composition of organic peroxides on SOA particles remains a great challenge and needs urgent study.

\section{Conclusions and atmospheric implications}

Our laboratory study has provided more evidence that organic peroxides are important components of SOA derived from the ozonolysis of alkenes. In the case of $\alpha$-pinene, organic peroxides account for $\sim 21 \%$ of the SOA mass and this fraction is not affected by $\mathrm{RH}$ and the presence of $\mathrm{OH}$ scavengers. More interestingly, the gas-particle partitioning coefficients of organic peroxides have been estimated for the first time based on the measurements of both gaseous and particulate peroxides. Due to the long time collection for SOA, these coefficients reported here are lower bounds in this study. For PFA and PAA, the observed values were $10^{4}$ times higher than that of the theoretical value calculated by the Pankow absorption model. This discrepancy indicates a more important role of peroxides in SOA formation than expected previously and the existence of mechanisms in addition to the absorption that are not yet defined. The reaction of organic hydroperoxides with carbonyls forming peroxyhemiacetals may explain part of the enhancement of the partitioning of peroxides. However, the kinetic parameters of peroxyhemiacetal formation are lacking. The explicit mechanisms of gas-particle partitioning and the determination of gas-particle partitioning coefficients of larger organic peroxides deserve further study to improve the simulation of SOA mass.

We also examined gas-phase peroxides. The yield of gaseous total peroxides was $\sim 0.22$, which was independent of $\mathrm{RH}$ and $\mathrm{OH}$ scavengers. The MCM v3.1 mechanism predicted this yield but failed to explain the yields of individual peroxides, i.e., $\mathrm{H}_{2} \mathrm{O}_{2}$, HMHP, PFA, and PAA, indicating that our previous understanding of $\alpha$-pinene ozonolysis was insufficient. For $\mathrm{H}_{2} \mathrm{O}_{2}$ with a yield of 0.048 under dry conditions and 0.16 under wet conditions, the known pathways, including dissolution of SOA, aqueous oxidation of gaseous compounds, and decomposition/hydrolysis of organic peroxides in the aqueous phase, cannot explain such an unexpectedly high yield of $\mathrm{H}_{2} \mathrm{O}_{2}$. The presence of both water and SOA leads to the rapid transformation of gaseous organic peroxides into $\mathrm{H}_{2} \mathrm{O}_{2}$. This heterogeneous process increases the $\mathrm{H}_{2} \mathrm{O}_{2}$ yield by $\sim 67 \%$. Our results also show that water vapor affects the distribution of gaseous peroxides, although it cannot change the yield of total peroxides.

The rapid heterogeneous transformation of organic peroxides to $\mathrm{H}_{2} \mathrm{O}_{2}$ helps to explain the differences between modeled and observed levels of peroxides and $\mathrm{OH}$ in the forest area. In the airborne GABRIEL field campaign in equatorial South America (Surinam) in October 2005 (Kubistin et al., 2010), two issues arose. (1) Organic peroxides were overestimated while $\mathrm{H}_{2} \mathrm{O}_{2}$ was underestimated, and (2) $\mathrm{OH}$ and $\mathrm{HO}_{2}$ were also underestimated, especially when concentrations of
VOCs were high. These investigators suggested the occurrence of additional recycling from $\mathrm{HO}_{2}$ to $\mathrm{OH}$ or the contributions of additional direct $\mathrm{OH}$ sources. Our finding that organic peroxides can transform to $\mathrm{H}_{2} \mathrm{O}_{2}$ by rapid heterogeneous reactions can address the first discrepancy directly and the second indirectly. Peroxides influence $\mathrm{OH}$ through the removal pathways as follows:

$$
\begin{aligned}
& \mathrm{ROOH}+h v \rightarrow \mathrm{RO}+\mathrm{OH} \\
& \mathrm{ROOH}+\mathrm{OH} \rightarrow \mathrm{RO}_{2}+\mathrm{H}_{2} \mathrm{O} \\
& \mathrm{H}_{2} \mathrm{O}_{2}+h v \rightarrow 2 \mathrm{OH} \\
& \mathrm{H}_{2} \mathrm{O}_{2}+\mathrm{OH} \rightarrow \mathrm{H}_{2} \mathrm{O}+\mathrm{HO}_{2} .
\end{aligned}
$$

Predominant removal paths for organic peroxides in the atmosphere are the reaction with $\mathrm{OH}(95 \%)$ and photolysis (4.4\%) (Khan et al., 2015), while for $\mathrm{H}_{2} \mathrm{O}_{2}$, these two paths are almost equally important. The $\mathrm{OH}$ oxidation process consumes $\mathrm{OH}$, while the photolysis process produces $\mathrm{OH}$. Obviously, $\mathrm{H}_{2} \mathrm{O}_{2}$ plays a different role in the $\mathrm{OH}$ cycling compared with organic peroxides. One molecule of organic peroxides, transformed into $\mathrm{H}_{2} \mathrm{O}_{2}$, yields $\sim 1.4$ molecules of $\mathrm{OH}$. Thus, the rapid transformation of organic peroxides to $\mathrm{H}_{2} \mathrm{O}_{2}$ by the heterogeneous process would increase $\mathrm{OH}$ levels. However, not all the organic peroxides could be transformed to $\mathrm{H}_{2} \mathrm{O}_{2}$ by the heterogeneous process. Further studies are needed to clarify this process in the atmosphere and unveil the features of the peroxides undergoing heterogeneous transformation.

\section{The Supplement related to this article is available online at doi:10.5194/acp-16-1837-2016-supplement.}

Acknowledgements. We gratefully acknowledge the National Natural Science Foundation of China (grants 41275125, 21190053 , 21477002) and the State Key Laboratory of Environment Simulation and Pollution Control (special fund) for financial support.

Edited by: F. Keutsch

\section{References}

Aplincourt, P. and Anglada, J.: Theoretical studies on isoprene ozonolysis under tropospheric conditions. 1. Reaction of substituted carbonyl oxides with water, J. Phys. Chem. A, 107, 57985811, doi:10.1021/jp026868o, 2003.

Arellanes, C., Paulson, S. E., Fine, P. M., and Sioutas, C.: Exceeding of Henry's law by hydrogen peroxide associated with urban aerosols, Environ. Sci. Technol., 40, 4859-4866, doi:10.1021/es0513786, 2006.

Badali, K. M., Zhou, S., Aljawhary, D., Antiñolo, M., Chen, W. J., Lok, A., Mungall, E., Wong, J. P. S., Zhao, R., and Abbatt, J. P. 
D.: Formation of hydroxyl radicals from photolysis of secondary organic aerosol material, Atmos. Chem. Phys., 15, 7831-7840, doi:10.5194/acp-15-7831-2015, 2015.

Banerjee, D. K. and Budke, C. C.: Spectrophotometric Determination of Traces of Peroxides in Organic Solvents, Anal. Chem., 36, 792-796, doi:10.1021/ac60210a027, 1964

Bateman, A. P., Nizkorodov, S. A., Laskin, J., and Laskin, A.: Photolytic processing of secondary organic aerosols dissolved in cloud droplets, Phys. Chem. Chem. Phys., 13, 12199-12212, doi:10.1039/c1cp20526a, 2011.

Baum, E.: Chemical property estimation: Theory and Application, CRC Press, Florida, 1997.

Becker, K. H., Brockmann, K. J., and Bechara, J.: Production of hydrogen peroxide in forest air by reaction of ozone with terpenes, Nature, 346, 256-258, doi:10.1038/346256a0, 1990.

Berndt, T., Böge, O., and Stratmann, F.: Gas-phase ozonolysis of $\alpha$-pinene: gaseous products and particle formation, Atmos. Environ., 37, 3933-3945, doi:10.1016/S1352-2310(03)00501-6, 2003.

Berndt, T., Voigtländer, J., Stratmann, F., Junninen, H., Mauldin III, R. L., Sipilä, M., Kulmala, M., and Herrmann, H.: Competing atmospheric reactions of $\mathrm{CH}_{2} \mathrm{OO}$ with $\mathrm{SO}_{2}$ and water vapour, Phys. Chem. Chem. Phys., 16, 19130-19136, doi:10.1039/c4cp02345e, 2014.

Bonn, B., von Kuhlmann, R., and Lawrence, M. G.: High contribution of biogenic hydroperoxides to secondary organic aerosol formation, Geophys. Res. Lett., 31, L10108, doi:10.1029/2003GL019172, 2004.

Camredon, M., Hamilton, J. F., Alam, M. S., Wyche, K. P., Carr, T., White, I. R., Monks, P. S., Rickard, A. R., and Bloss, W. J.: Distribution of gaseous and particulate organic composition during dark a-pinene ozonolysis, Atmos. Chem. Phys., 10, 2893-2917, doi:10.5194/acp-10-2893-2010, 2010.

Chao, W., Hsieh, J.-T., and Chang, C.-H.: Direct kinetic measurement of the reaction of the simplest Criegee intermediate with water vapor, Science, 347, 751-754, doi:10.1126/science.1261549, 2015.

Chen, Z. M., Wang, H. L., Zhu, L. H., Wang, C. X., Jie, C. Y., and Hua, W.: Aqueous-phase ozonolysis of methacrolein and methyl vinyl ketone: a potentially important source of atmospheric aqueous oxidants, Atmos. Chem. Phys., 8, 2255-2265, doi:10.5194/acp-8-2255-2008, 2008.

Cocker III, D. R., Clegg, S. L., Flagan, R. C., and Seinfeld, J. H.: The effect of water on gas-particle partitioning of secondary organic aerosol. Part I: $\alpha$-pinene/ozone system, Atmos. Environ., 35, 6049-6072, doi:10.1016/S1352-2310(01)00404-6, 2001.

Crehuet, R., Anglada, J. M., and Bofill, J. M.: Tropospheric formation of hydroxymethyl hydroperoxide, formic acid, $\mathrm{H}_{2} \mathrm{O}_{2}$, and $\mathrm{OH}$ from carbonyl oxide in the presence of water vapor: a theoretical study of the reaction mechanism, Chemistrya European Journal, 7, 2227-2235, doi:10.1002/15213765(20010518)7:10<2227::AID-CHEM2227>3.3.CO;2-F, 2001

Docherty, K. S., Wu, W., Lim, Y. B., and Ziemann, P. J.: Contributions of organic peroxides to secondary aerosol formed from reactions of monoterpenes with $\mathrm{O}_{3}$, Environ. Sci. Technol., 39, 4049-4059, doi:10.1021/es050228s, 2005.

Epstein, S. A., Blair, S. L., and Nizkorodov, S. A.: Direct photolysis of $\alpha$-pinene ozonolysis secondary organic aerosol: effect on particle mass and peroxide content, Environ. Sci. Technol., 48, 11251-11258, doi:10.1021/es502350u, 2014.

Farina, S. C., Adams, P. J., and Pandis, S. N.: Modeling global secondary organic aerosol formation and processing with the volatility basis set: Implications for anthropogenic secondary organic aerosol, J. Geophys. Res.-Atmos., 115, D09202, doi:10.1029/2009JD013046, 2010.

Fu, H. B., Wang, X., Wu, H. B., Yin, Y., and Chen, J. M.: Heterogeneous uptake and oxidation of $\mathrm{SO}_{2}$ on iron oxides, J. Phys. Chem. C, 111, 6077-6085, doi:10.1021/jp070087b, 2007.

Gäb, S., Turner, W. V., Wolff, S., Becker, K. H., Ruppert, L., and Brockmann, K. J.: Formation of alkyl and hydroxyalkyl hydroperoxides on ozonolysis in water and in air, Atmos. Environ., 29, 2401-2407, doi:10.1016/1352-2310(95)00166-V, 1995.

Goodman, A., Bernard, E., and Grassian, V.: Spectroscopic study of nitric acid and water adsorption on oxide particles: Enhanced nitric acid uptake kinetics in the presence of adsorbed water, J. Phys. Chem. A, 105, 6443-6457, doi:10.1021/jp0037221, 2001.

Griffin, R. J., Cocker, D. R., Flagan, R. C., and Seinfeld, J. H.: Organic aerosol formation from the oxidation of biogenic hydrocarbons, J. Geophys. Res., 104, 3555-3567, doi:10.1029/1998JD100049, 1999.

Hellpointner, E. and Gäb, S.: Detection of methyl, hydroxymethyl and hydroxyethyl hydroperoxides in air and precipitation, Nature, 337, 631-634, doi:10.1038/337631a0, 1989.

Hewitt, C. N. and Kok, G. L.: Formation and occurrence of organic hydroperoxides in the troposphere: laboratory and field observations, J. Atmos. Chem., 12, 181-194, doi:10.1007/BF00115779, 1991.

Hoffmann, T., Odum, J. R., Bowman, F., Collins, D., Klockow, D., Flagan, R. C., and Seinfeld, J. H.: Formation of organic aerosols from the oxidation of biogenic hydrocarbons, J. Atmos. Chem., 26, 189-222, doi:10.1023/A:1005734301837, 1997.

Hua, W., Chen, Z. M., Jie, C. Y., Kondo, Y., Hofzumahaus, A., Takegawa, N., Chang, C. C., Lu, K. D., Miyazaki, Y., Kita, K., Wang, H. L., Zhang, Y. H., and Hu, M.: Atmospheric hydrogen peroxide and organic hydroperoxides during PRIDE-PRD'06, China: their concentration, formation mechanism and contribution to secondary aerosols, Atmos. Chem. Phys., 8, 6755-6773, doi:10.5194/acp-8-6755-2008, 2008.

Huang, D., Chen, Z. M., Zhao, Y., and Liang, H.: Newly observed peroxides and the water effect on the formation and removal of hydroxyalkyl hydroperoxides in the ozonolysis of isoprene, Atmos. Chem. Phys., 13, 5671-5683, doi:10.5194/acp-13-56712013, 2013.

Huang, L. B., Zhao, Y., Li, H., and Chen, Z. M.: Kinetics of heterogeneous reaction of sulfur dioxide on authentic mineral dust: effects of relative humidity and hydrogen peroxide, Environ. Sci Technol., 49, 10797-10805, doi:10.1021/acs.est.5b03930, 2015.

Jenkin, M. E.: Modelling the formation and composition of secondary organic aerosol from $\alpha$ - and $\beta$-pinene ozonolysis using MCM v3, Atmos. Chem. Phys., 4, 1741-1757, doi:10.5194/acp4-1741-2004, 2004.

Kamens, R. M. and Jaoui, M.: Modeling aerosol formation from $\alpha$-pinene $+\mathrm{NO}_{x}$ in the presence of natural sunlight using gasphase kinetics and gas-particle partitioning theory, Environ. Sci. Technol., 35, 1394-1405, doi:10.1021/es001626s, 2001.

Khan, M., Cooke, M., Utembe, S., Xiao, P., Morris, W., Derwent, R., Archibald, A., Jenkin, M., Percival, C., and Shall- 
cross, D.: The global budgets of organic hydroperoxides for present and pre-industrial scenarios, Atmos. Environ., 110, 6574, doi:10.1016/j.atmosenv.2015.03.045, 2015.

Kidd, C., Perraud, V., and Finlayson-Pitts, B. J.: New insights into secondary organic aerosol from the ozonolysis of $\alpha$-pinene from combined infrared spectroscopy and mass spectrometry measurements, Phys. Chem. Chem. Phys., 16, 22706-22716, doi:10.1039/c4cp03405h, 2014.

Kroll, J. H., Ng, N. L., Murphy, S. M., Varutbangkul, V., Flagan, R. C., and Seinfeld, J. H.: Chamber studies of secondary organic aerosol growth by reactive uptake of simple carbonyl compounds, J. Geophys. Res.-Atmos., 110, D23207, doi:10.1029/2005JD006004, 2005.

Kubistin, D., Harder, H., Martinez, M., Rudolf, M., Sander, R., Bozem, H., Eerdekens, G., Fischer, H., Gurk, C., Klüpfel, T., Königstedt, R., Parchatka, U., Schiller, C. L., Stickler, A., Taraborrelli, D., Williams, J., and Lelieveld, J.: Hydroxyl radicals in the tropical troposphere over the Suriname rainforest: comparison of measurements with the box model MECCA, Atmos. Chem. Phys., 10, 9705-9728, doi:10.5194/acp-10-97052010, 2010.

Lee, M., Heikes, B. G., and O'Sullivan, D. W.: Hydrogen peroxide and organic hydroperoxide in the troposphere: a review, Atmos. Environ., 34, 3475-3494, doi:10.1016/S1352-2310(99)00432-X, 2000.

Lewis, T. R., Blitz, M. A., Heard, D. E., and Seakins, P. W.: Direct evidence for a substantive reaction between the Criegee intermediate, $\mathrm{CH}_{2} \mathrm{OO}$, and the water vapour dimer, Phys. Chem. Chem. Phys., 17, 4859-4863, doi:10.1039/c4cp04750h, 2015.

Liggio, J., Li, S.-M., and McLaren, R.: Heterogeneous reactions of glyoxal on particulate matter: Identification of acetals and sulfate esters, Environ. Sci. Technol., 39, 1532-1541, doi:10.1021/es048375y, 2005.

Mertes, P., Pfaffenberger, L., Dommen, J., Kalberer, M., and Baltensperger, U.: Development of a sensitive long path absorption photometer to quantify peroxides in aerosol particles (PeroxideLOPAP), Atmos. Meas. Tech., 5, 2339-2348, doi:10.5194/amt5-2339-2012, 2012.

Nguyen, T. B., Bateman, A. P., Bones, D. L., Nizkorodov, S. A., Laskin, J., and Laskin, A.: High-resolution mass spectrometry analysis of secondary organic aerosol generated by ozonolysis of isoprene, Atmos. Environ., 44, 1032-1042, doi:10.1016/j.atmosenv.2009.12.019, 2010.

Odum, J. R., Hoffmann, T., Bowman, F., Collins, D., Flagan, R. C., and Seinfeld, J. H.: Gas/particle partitioning and secondary organic aerosol yields, Environ. Sci. Technol., 30, 2580-2585, doi:10.1021/es950943+, 1996.

Pankow, J. F.: An absorption model of the gas/aerosol partitioning involved in the formation of secondary organic aerosol, Atmos. Environ., 28, 189-193, doi:10.1016/1352-2310(94)900930, 1994.

Presto, A. A., Huff Hartz, K. E., and Donahue, N. M.: Secondary organic aerosol production from terpene ozonolysis. 2. Effect of $\mathrm{NO}_{x}$ concentration, Environ. Sci. Technol., 39, 7046-7054, doi:10.1021/es050400s, 2005.

Prince, A. P., Kleiber, P., Grassian, V., and Young, M.: Heterogeneous interactions of calcite aerosol with sulfur dioxide and sulfur dioxide-nitric acid mixtures, Phys. Chem. Chem. Phys., 9, 3432-3439, doi:10.1039/B703296J, 2007.
Pye, H. O. T. and Seinfeld, J. H.: A global perspective on aerosol from low-volatility organic compounds, Atmos. Chem. Phys., 10, 4377-4401, doi:10.5194/acp-10-4377-2010, 2010.

Reeves, C. E. and Penkett, S. A.: Measurements of peroxides and what they tell us, Chem. Rev., 103, 5199-5218, doi:10.1021/cr0205053, 2003.

Rudich, Y., Donahue, N. M., and Mentel, T. F.: Aging of organic aerosol: Bridging the gap between laboratory and field studies, Annu. Rev. Phys. Chem., 58, 321-352, doi:10.1146/annurev.physchem.58.032806.104432, 2007.

Ryzhkov, A. B. and Ariya, P. A.: A theoretical study of the reactions of parent and substituted Criegee intermediates with water and the water dimer, Phys. Chem. Chem. Phys., 6, 5042-5050, doi:10.1039/B408414D, 2004.

Saathoff, H., Naumann, K.-H., Möhler, O., Jonsson, ̊̊. M., Hallquist, M., Kiendler-Scharr, A., Mentel, Th. F., Tillmann, R., and Schurath, U.: Temperature dependence of yields of secondary organic aerosols from the ozonolysis of a-pinene and limonene, Atmos. Chem. Phys., 9, 1551-1577, doi:10.5194/acp-9-1551-2009, 2009.

Simonaitis, R., Olszyna, K., and Meagher, J.: Production of hydrogen peroxide and organic peroxides in the gas phase reactions of ozone with natural alkenes, Geophys. Res. Lett., 18, 9-12, 1991.

Surratt, J. D., Murphy, S. M., Kroll, J. H., Ng, N. L., Hildebrandt, L., Sorooshian, A., Szmigielski, R., Vermeylen, R., Maenhaut, W., and Claeys, M.: Chemical composition of secondary organic aerosol formed from the photooxidation of isoprene, J. Phys. Chem. A, 110, 9665-9690, doi:10.1021/jp061734m, 2006.

Tobias, H. J. and Ziemann, P. J.: Thermal desorption mass spectrometric analysis of organic aerosol formed from reactions of 1-tetradecene and $\mathrm{O}_{3}$ in the presence of alcohols and carboxylic acids, Environ. Sci. Technol., 34, 2105-2115, doi:10.1021/es9907156, 2000.

Tobias, H. J. and Ziemann, P. J.: Kinetics of the gas-phase reactions of alcohols, aldehydes, carboxylic acids, and water with the $\mathrm{C}_{13}$ stabilized Criegee intermediate formed from ozonolysis of 1-tetradecene, J. Phys. Chem. A, 105, 6129-6135, doi:10.1021/jp004631r, 2001.

Venkatachari, P. and Hopke, P. K.: Development and laboratory testing of an automated monitor for the measurement of atmospheric particle-bound reactive oxygen species (ROS), Aerosol Sci. Tech., 42, 629-635, doi:10.1039/b804357d, 2008.

Vereecken, L., Harder, H., and Novelli, A.: The reactions of Criegee intermediates with alkenes, ozone, and carbonyl oxides, Phys Chem. Chem. Phys., 16, 4039-4049, doi:10.1039/c3cp54514h, 2014.

Wang, Y., Kim, H., and Paulson, S. E.: Hydrogen peroxide generation from $\alpha$-and $\beta$-pinene and toluene secondary organic aerosols, Atmos. Environ., 45, 3149-3156, doi:10.1016/j.atmosenv.2011.02.060, 2011.

Yu, J. Z., Cocker III, D. R., Griffin, R. J., Flagan, R. C., and Seinfeld, J. H.: Gas-phase ozone oxidation of monoterpenes: Gaseous and particulate products, J. Atmos. Chem., 34, 207-258, doi:10.1023/A:1006254930583, 1999.

Zhang, X., Chen, Z. M., Wang, H. L., He, S. Z., and Huang, D. M.: An important pathway for ozonolysis of alpha-pinene and beta-pinene in aqueous phase and its atmospheric implications, Atmos. Environ., 43, 4465-4471, doi:10.1016/j.atmosenv.2009.06.028, 2009. 
Zhao, Y., Chen, Z. M., and Zhao, J. N.: Heterogeneous reactions of methacrolein and methyl vinyl ketone on $\alpha-\mathrm{Al}_{2} \mathrm{O}_{3}$ particles, Environ. Sci. Technol., 44, 2035-2041, doi:10.1021/es9037275, 2010.

Zhao, Y., Chen, Z. M., Shen, X. L., and Zhang, X.: Kinetics and mechanisms of heterogeneous reaction of gaseous hydrogen peroxide on mineral oxide particles, Environ. Sci. Technol., 45, 3317-3324, doi:10.1021/es104107c, 2011.

Zhao, Y., Huang, D., Huang, L. B., and Chen, Z. M.: Hydrogen peroxide enhances the oxidation of oxygenated volatile organic compounds on mineral dust particles: a case study of methacrolein, Environ. Sci. Technol., 48, 10614-10623, doi:10.1021/es5023416, 2014.
Zhou, X. L. and Lee, Y. N.: Aqueous solubility and reaction kinetics of hydroxymethyl hydroperoxide, J. Phys. Chem., 96, 265-272, doi:10.1021/j100180a051, 1992.

Ziemann, P. J.: Aerosol products, mechanisms, and kinetics of heterogeneous reactions of ozone with oleic acid in pure and mixed particles, Faraday Discuss., 130, 469-490, doi:10.1039/b417502f, 2005. 